\title{
Suppression of the auxin response pathway enhances susceptibility to Phytophthora cinnamomi while phosphite-mediated resistance stimulates the auxin signalling pathway
}

\author{
Leila Eshraghi ${ }^{1^{*}}$, Jonathan P Anderson ${ }^{2,4}$, Nader Aryamanesh ${ }^{3,4}$, Jen A McComb ${ }^{1}$, Bryan Shearer ${ }^{1,5}$ \\ and Giles E St J Hardy ${ }^{1}$
}

\begin{abstract}
Background: Phytophthora cinnamomi is a devastating pathogen worldwide and phosphite (Phi), an analogue of phosphate (Pi) is highly effective in the control of this pathogen. Phi also interferes with Pi starvation responses (PSR), of which auxin signalling is an integral component. In the current study, the involvement of $\mathrm{Pi}$ and the auxin signalling pathways in host and Phi-mediated resistance to $P$. cinnamomi was investigated by screening the Arabidopsis thaliana ecotype Col-0 and several mutants defective in PSR and the auxin response pathway for their susceptibility to this pathogen. The response to Phi treatment was also studied by monitoring its effect on Pi- and the auxin response pathways.

Results: Here we demonstrate that phr1-1 (phosphate starvation response 1), a mutant defective in response to Pi starvation was highly susceptible to $P$. cinnamomi compared to the parental background Col-0. Furthermore, the analysis of the Arabidopsis tir1-1 (transport inhibitor response 1) mutant, deficient in the auxin-stimulated SCF (Skp1 - Cullin - F-Box) ubiquitination pathway was also highly susceptible to $P$. cinnamomi and the susceptibility of the mutants rpn 10 and pbe 1 further supported a role for the 265 proteasome in resistance to $P$. cinnamomi. The role of auxin was also supported by a significant $(P<0.001)$ increase in susceptibility of blue lupin (Lupinus angustifolius) to P. cinnamomi following treatment with the inhibitor of auxin transport, TIBA (2,3,5-triiodobenzoic acid). Given the apparent involvement of auxin and PSR signalling in the resistance to $P$. cinnamomi, the possible involvement of these pathways in Phi mediated resistance was also investigated. Phi (especially at high concentrations) attenuates the response of some Pi starvation inducible genes such as AT4, AtACP5 and AtPT2 in Pi starved plants. However, Phi enhanced the transcript levels of PHR1 and the auxin responsive genes (AUX1, AXR1and AXR2), suppressed the primary root elongation, and increased root hair formation in plants with sufficient $\mathrm{Pi}$.
\end{abstract}

Conclusions: The auxin response pathway, particularly auxin sensitivity and transport, plays an important role in resistance to $P$. cinnamomi in Arabidopsis, and phosphite-mediated resistance may in some part be through its effect on the stimulation of the PSR and auxin response pathways.

Keywords: Abscisic acid, Indole-3-acetic acid (IAA), Phosphate starvation response (PSR), TIBA, Ubiquitin proteasome pathway (UPP)

\footnotetext{
* Correspondence: L.Eshraghi@murdoch.edu.au

${ }^{1}$ Centre for Phytophthora Science and Management, School of Veterinary and Life Sciences, Murdoch University, South Street, Murdoch, WA 6150,

Australia

Full list of author information is available at the end of the article
}

\section{Biomed Central}

(c) 2014 Eshraghi et al.; licensee BioMed Central Ltd. This is an Open Access article distributed under the terms of the Creative Commons Attribution License (http://creativecommons.org/licenses/by/2.0), which permits unrestricted use, distribution, and reproduction in any medium, provided the original work is properly credited. The Creative Commons Public Domain Dedication waiver (http://creativecommons.org/publicdomain/zero/1.0/) applies to the data made available in this article, unless otherwise stated. 


\section{Background}

The plant pathogen Phytophthora cinnamomi causes considerable damage to agriculture, horticulture and native plant communities worldwide [1-6]. Phosphite (Phi), an analogue of phosphate $(\mathrm{Pi})$ is a salt of phosphorous acid $\left(\mathrm{H}_{3} \mathrm{PO}_{3}\right)$ and is highly effective in controlling $P$. cinnamomi $[3,5,7,8]$. However, little is known about the mode of action of Phi on induction of resistance to this pathogen. Understanding the molecular mechanisms underlying plant-Phytophthora cinnamomi interactions and the effect of Phi on these interactions may allow the design of strategies to improve disease resistance or the more effective use of Phi.

Resistance to potential pathogens depends on interaction between different plant defence signalling pathways such as those regulated by the phytohormones salicylic acid (SA), jasmonic acid (JA), ethylene (ET), abscisic acid (ABA), and auxin [9]. Synergistic and antagonistic interactions between different signalling pathways induced by phytohormones and their effect on induction of resistance to biotrophic or necrotrophic pathogens have been well documented [9-14].

Phi is believed to mimic $\mathrm{Pi}$ and interferes with the manifestation of a wide range of biochemical and developmental Pi starvation responses (PSR) in Arabidopsis thaliana and other plant species [15-18]. Pi status is very important for determining root architecture mediated through the auxin signalling pathway and auxin signalling is required for the full Pi starvation response [19-23].

Auxin signalling is mediated largely by the SCF ${ }^{\text {TIR1 }}$ E3 ubiquitin ligase complex (UPP complex) that accelerates AUXIN/INDOLE-3-ACETIC ACID (AUX/IAA) repressor protein degradation in response to auxin [24-27]. The AUX/IAA repressor proteins are recognized and ubiquitinated by a ubiquitin-conjugation cycle involving an E1 (AXR1 and ECR1), an E2 (RCE1), and the SCF ${ }^{\mathrm{TIR} 1} \mathrm{E} 3$, which consists of a Cullin-CUL1, the SKP1-ASK1, RBX1, and the F-Box protein TIR1 (TRANSPORT INHIBITOR RESPONSE1) [28]. Pi modulates auxin sensitivity via the auxin receptor TIR 1 and Pi starvation increases the expression of the TIR1 gene in Arabidopsis seedlings leading to degradation of AUX/IAA repressors and activation of downstream auxin responses [24,25]. SGT1B protein functions in SCF-TIR1 mediated degradation of AUX/IAA proteins [29-31] and interacts with RAR1; a component of R-gene-mediated resistance [31-33]. Both RAR1 and SGT1B interact with COP9 which is involved in protein degradation by the $26 \mathrm{~S}$ proteasome [32,34]. Furthermore, auxin has been implicated in the induction of resistance against some necrotrophic pathogens including Plectosphaerella cucumerina and Botrytis cinerea [9,35].

In conclusion, the involvement of the auxin signalling pathway in plant defence and Pi signalling, together with interference of Phi in Pi homeostasis and PSR indicates a possible involvement of the auxin signalling pathway in resistance of some Arabidopsis accessions to $P$. cinnamomi, previously reported to possess a predominantly necrotrophic lifestyle [36] and in Phi mediated resistance. The objectives of this study were to examine the potential involvement of $\mathrm{Pi}$ and auxin signalling pathways in resistance to $P$. cinnamomi by screening the mutants defective in PSR, auxin and ubiquitin signalling pathways for their susceptibility to this pathogen and to investigate whether Phi induces resistance to $P$. cinnamomi by manipulating the PSR and auxin signalling pathways by studying the effect of Phi on Pi signalling and the importance of their concomitant effect on activation/suppression of the auxin response pathway in relation to PSR. The mechanism of action of Phi was further examined by investigating its effect on morphological PSR responses and analysis of Pi starvation gene expression following Phi treatment under Pi sufficient and deficient conditions and in auxin and ABA response modulation of Pi signalling involving auxin.

\section{Results}

Resistance to $P$. cinnamomi was reduced in the $\mathbf{P i}$ starvation response mutant

To investigate whether Pi signalling affects the response of Arabidopsis to P. cinnamomi, ecotype Col-0 and several PSR mutants phr1-1, pho2-1, and pho1-2 were screened for their susceptibility to the pathogen and the level of infection was determined quantitatively according to Eshraghi et al. [37]. The QPCR analysis of infection showed significantly $(P<0.001)$ greater $P$. cinnamomi biomass in the phr1-1 mutant compared to that in its wild background Col-0 (Figure 1) suggesting a role of $\mathrm{Pi}$ signalling in resistance to $P$. cinnamomi. Furthermore, transferring the cloned PHR1 gene into the susceptible phr1-1 mutant restored resistance to the level observed in the parental background Col-0 (Figure 1) confirming that the mutant was susceptible due to loss of PHR1 function. The PHR1 gene contributes to downstream Pi signalling by regulating the expression of Pi responsive genes [38-40] and the phr1 mutant is defective in Pi signalling [38]. PHO1 and PHO2 both act downstream of the PHR1 transcription factor to control the local uptake or transport of Pi [41-44]. The pho2-1 and pho1-2 mutants did not show significant $(P>0.05)$ increase in their susceptibility to $P$. cinnamomi compared to Col-0 (Figure 1).

\section{The SCF ${ }^{\text {TIR1 }}$ complex is involved in resistance to $P$. cinnamomi infection}

The high susceptibility of the phr1-1 mutant in the current study, combined with the role of the auxin signalling pathway in the PSR and plant resistance $[19,35]$ suggested a possible involvement of auxin signalling in 


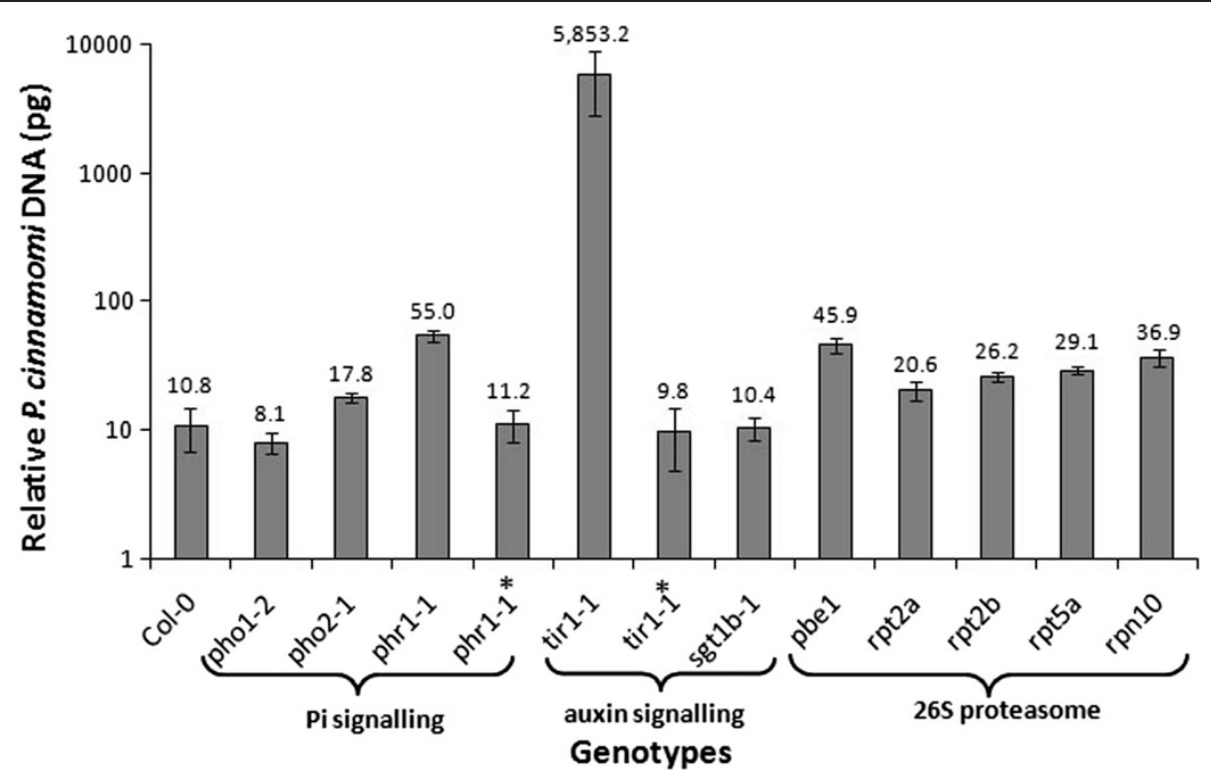

Figure 1 Phytophthora cinnamomi response in several mutants of Arabidopsis thaliana defective in auxin signalling, phosphate signalling and $26 \mathrm{~S}$ proteasome subunits. Quantitative PCR (QPCR) assessment of Phytophthora cinnamomi biomass (pg DNA per sample) $72 \mathrm{~h}$ after inoculation of attached leaves of Arabidopsis thaliana ecotype Colombia (Col-0) and several Arabidopsis mutants defective in Pi signalling (pho 1-1, pho2-1, and phr1-1), the auxin signalling pathway (tir 1-1and sqt1b-1), and 265 proteasome subunits (pbe1, rpt2a, rpt2b, rpt5a and rpn 10). Bars represent the mean and standard error from five replicates each consisting of four infected leaves. One way ANOVA indicated a significant $(P<0.001)$ difference between genotypes. LSD (5\%) was 8.92. phr1-1* $=$ phr1-1 mutant complemented with PHR1 gene (AT4G28610) and tir1-1* $=$ tir1-1 mutant complemented with TIR1gene (AT3G62980).

resistance to $P$. cinnamomi. QPCR assessment of pathogen biomass showed that tir1-1; an auxin response mutant deficient in the auxin-stimulated SCF (Skp1 Cullin - F-Box) ubiquitination pathway [45-48] was highly susceptible to $P$. cinnamomi (Figure 1). Furthermore, transferring the cloned TIR1 gene into the tir1-1 mutant restored resistance to the level observed in the parental background Col-0 (Figure 1) and confirmed that susceptibility was due to loss of TIR1 function in the mutant.

Since Arabidopsis SGT1B contributes to the auxin response controlled by the $\mathrm{SCF}^{\mathrm{TIR} 1}$ complex $[30,45]$ and functions in plant disease resistance signalling [29], we investigated whether mutations in SGT1B also affect resistance to $P$. cinnamomi. QPCR analysis showed no significant $(P>0.05)$ differences in susceptibility of sgt $1 b-1$ in comparison to its wild parental background Col-0 (Figure 1) suggesting that SGT1B does not contribute to SCF-related processes in resistance to $P$. cinnamomi.

\section{The $26 \mathrm{~S}$ proteasome subunits are involved in resistance to $P$. cinnamomi}

The $26 \mathrm{~S}$ proteasome is involved in the degradation of AUX/IAA proteins and consequently activation of auxin responsive genes [49]. In the present study, several Arabidopsis mutants defective in $26 \mathrm{~S}$ proteasome subunits (pbe1, rpt2a, rpt2b, rpt5a and rpn10) were screened for their susceptibility to P. cinnamomi. The analysis of infection revealed that the Arabidopsis mutants pbe1, a knockout mutant for $20 \mathrm{~S}$ proteasome [50] and rpn10 with reduced auxin sensitivity [51] were both significantly $(P<0.001)$ more susceptible to $P$. cinnamomi compared to their parental background Col-0, with 45.9 and 36.9 pathogen biomass (pg DNA), respectively (Figure 1). Furthermore, the susceptibility of the Arabidopsis $26 \mathrm{~S}$ proteasome subunit mutants rpt5a (29.1 pg), rpt2a (20.6 pg), and $r p t 2 b$ (homologue of $r p t 2 a ; 26.2 \mathrm{pg}$ ) was significantly $(P<0.001)$ higher compared to that in their background Col-0 (10.8 pg, Figure 1).

\section{Inhibition of auxin transport by TIBA treatments enhanced $P$. cinnamomi infection}

The susceptibility of the Arabidopsis auxin response mutant tir1-1 [35] suggested the involvement of auxin response pathway in the outcome of $A$. thaliana-P. cinnamomi resistance (Figure 1). To test this further, blue lupin (susceptible to $P$. cinnamomi) seedlings were treated with an auxin transport inhibitor, TIBA, and their susceptibility determined. For these studies we used blue lupin rather than Arabidopsis because of the large size of the root system and susceptibility to $P$. cinnamomi allowing clearer observation of potential differences. Infection in lupin seedling roots treated with TIBA was significantly $(P<0.001)$ greater than in nontreated plants $72 \mathrm{~h}$ after inoculation (Figure 2). 

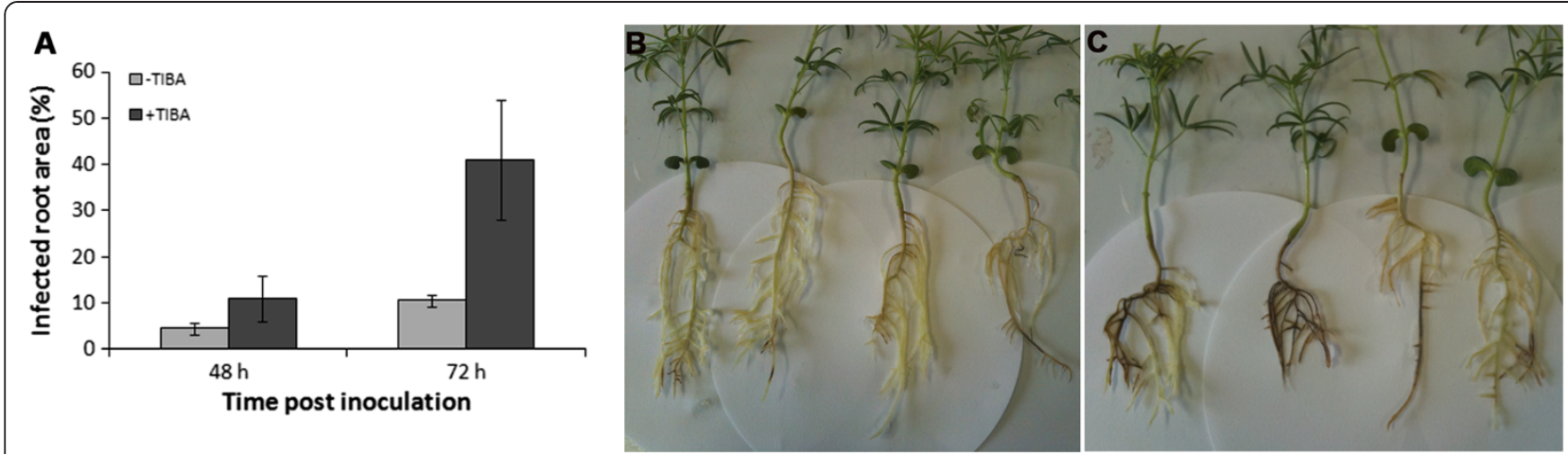

Figure 2 Negative effect of auxin transporter inhibitor (TIBA) on Phytophthora cinnamomi resistance in lupin. The effect of TIBA; an auxin transport inhibitor on lesion development in Lupinus angustifolius roots inoculated with Phytophthora cinnamomi mycelial plugs. (A) Percentage infected root area in TIBA-treated (+TIBA) and non-TIBA-treated (-TIBA) lupin roots $48 \mathrm{~h}$ and $72 \mathrm{~h}$ after inoculation. (B) and (C) show disease symptoms caused by $P$. cinnamomi infection in non-TIBA-treated (B) and TIBA-treated (C). One way ANOVA indicated a significant $(P<0.001)$ difference between treatments.

\section{Expression of Pi-and auxin signalling-related genes in response to Phi treatments}

The relative expression ratios of the Pi responsive genes AtPT2, AtACP5 and AT4 (Additional file 1: Table S1) in Col-0 grown under Pi sufficient or Pi deficient conditions were analysed following Phi treatments (Table 1). The transcript levels of AT4, AtPT2, and AtACP5 increased significantly $(P<0.001)$ in response to Pi deficiency in wild ecotype Col-0 (Table 1). In contrast, the transcript levels of the AT4, AtPT2, and AtACP5 genes were greatly suppressed (55.6-fold, 8.9-fold, and 4.2-fold, respectively) when the $\mathrm{Pi}$ starved plants were treated with $2.5 \mathrm{mM}$ Phi. Furthermore, the high level of Phi $(20 \mathrm{mM})$ suppressed the up-regulation of AT4 (1.1-fold), ATPT2 (1.1-fold), and AtACP5 (1.07-fold) in response to Pi deficiency to the levels observed in plants grown in Pi sufficient (control) conditions demonstrating an impact of Phi on the PSR (Table 1).

Given the apparent involvement of the $\mathrm{Pi}$ and auxin signalling pathways in the resistance of Col-0, the interaction of these pathways with ABA signalling [42] and previous observations of the susceptibility of ABA signalling mutants by Eshraghi et al. [52], the effects of Phi treatment on PSR gene expression was investigated in Col-0, aba2-4 and tir1-1 plants (Figure 3). The transcript level of the AT4 in Pi deficient, non-Phi-treated Col-0, aba2-4 and tir1-1 significantly $(P<0.05)$ increased 100-fold, 112-fold, and 111-fold, respectively compared to Pi sufficient Col-0. However, Phi treatments resulted in suppression of the AT4 gene in all plants tested with the level of this suppression depended on the concentration of Phi applied (Figure 3).

In non-Phi-treated Col-0, the transcript level of PHR1 (phosphate starvation response 1) in response to Pi deficiency increased (2.7-fold) and Phi treatments suppressed the transcript level of this gene with the highest suppression in $20 \mathrm{mM}$ Phi-treated plants (Figure 3). Although Phi treatment in Pi deficient grown samples suppressed the expression of PHR1, the transcript level of this gene was induced in Col-0 samples grown in $\mathrm{Pi}$ sufficient media and the level of this induction depended on the concentration of Phi applied in this study (Figure 3). The expression of PHR1 in response to Pi starvation was diminished in aba2-4 and tir1-1 mutants compared to that in Col-0 indicating the importance of $A B A 2$ and TIR1 genes in induction of PHR1. Furthermore, Phi treatments had no significant $(P>0.05)$ effect on transcript level of the PHR1 gene in either the aba2-4 or tir1-1 mutants suggesting that mutation in ABA2 and TIR1 genes may disrupt the Phi effect on Pi signalling.

The high susceptibility of the Arabidopsis mutant tir1-1 (Figure 1) and the enhanced level of P. cinnamomi infection in roots of TIBA-treated lupins (Figure 2) showed that the auxin response pathway plays an important role in resistance to $P$. cinnamomi. In addition, the induction of PHR1 gene by Phi in Col-0 samples grown in Pi sufficient media suggested that Phi induces PSR and loss of PHR1 gene expression in the tir1-1 mutant highlighted the possible induction of the auxin response pathway by Phi treatments. Therefore, we hypothesised that Phi mediated resistance to $P$. cinnamomi may be through induction of the auxin response pathway.

To test this hypothesis, the concomitant effect of Phi and $\mathrm{Pi}$ on auxin signalling in $\mathrm{Pi}$ sufficient/Pi deficient grown Col-0, aba2-4 and tir1-1 mutants following 0, 0.5, 2.5 and $20 \mathrm{mM}$ Phi treatments was assessed by measuring the relative expression ratios of auxin responsive genes, $A U X 1, A X R 1, A X R 2$ and SGT1B transcripts (Additional file 1: Table S1). In non-Phi-treated Col-0 seedlings, Pi deficiency increased the transcript levels of $A U X 1$ (2.3-fold), AXR1 (2.9-fold), AXR2 (2.8-fold) and SGT1B (2.3-fold) genes indicating activation of the auxin response pathway 
Table 1 Expression analysis of phosphate starvation response (PSR) genes in Arabidopsis thaliana ecotype Columbia (Col-0) grown under phosphate (Pi) sufficient $(+\mathrm{Pi} ; 1.25 \mathrm{mM})$ and $\mathrm{Pi}$ deficient $(-\mathrm{Pi} ; 0 \mathrm{mM})$ conditions and subjected to different phosphite (Phi) treatments

\begin{tabular}{|c|c|c|c|c|c|c|c|c|c|c|c|}
\hline \multirow[b]{3}{*}{$\mathrm{Gene}^{\mathrm{a}}$} & \multicolumn{6}{|c|}{ Normalized relative transcript level } & \multicolumn{5}{|c|}{ Relative fold difference to control } \\
\hline & \multicolumn{3}{|c|}{$+\mathrm{Pi}$} & \multicolumn{3}{|c|}{$-\mathrm{Pi}$} & \multicolumn{2}{|c|}{$+\mathrm{Pi}$} & \multicolumn{3}{|c|}{$-\mathrm{Pi}$} \\
\hline & 0 mM Phi (control) & $2.5 \mathrm{mM}$ Phi & $20 \mathrm{mM}$ Phi & $0 \mathrm{mM}$ Phi & $2.5 \mathrm{mM}$ Phi & $20 \mathrm{mM}$ Phi & $2.5 \mathrm{mM}$ Phi & $20 \mathrm{mM}$ Phi & $0 \mathrm{mM}$ Phi & $2.5 \mathrm{mM}$ Phi & $20 \mathrm{mM}$ Phi \\
\hline AT4 & $0.261_{ \pm 0.005}$ & $0.175 \pm 0.013$ & $0.306 \pm 0.033$ & $73.127_{ \pm} 4.331$ & $14.512 \pm 0.264$ & $0.290 \pm 0.026$ & 0.7 & 1.2 & 280.4 & 55.6 & 1.11 \\
\hline AtPT2 & $0.449 \pm 0.011$ & $0.662 \pm 0.112$ & $0.527 \pm 0.016$ & $12.537 \pm 0.70$ & $3.979 \pm 0.126$ & $0.499 \pm 0.082$ & 1.5 & 1.2 & 27.9 & 8.9 & 1.11 \\
\hline AtACP5 & $0.429+0.008$ & $0.560+0.032$ & $0.432 \pm 0.005$ & $8.354+0.434$ & $1.803+0.049$ & $0.459 \pm 0.007$ & 1.3 & 1.0 & 19.5 & 4.2 & 1.07 \\
\hline
\end{tabular}

The transcript level of genes was normalized based on the expression of actin 2 (ACT2) measured in the same samples and presented as both normalized relative transcript level (mean \pm SE) and the factor of increase in transcription compared with the control (+Pi/0 mM Phi). Data represent the mean and standard error of four biological replicates per treatment each consisting of three plants.

${ }^{\mathrm{a}}$ See Table 2. 

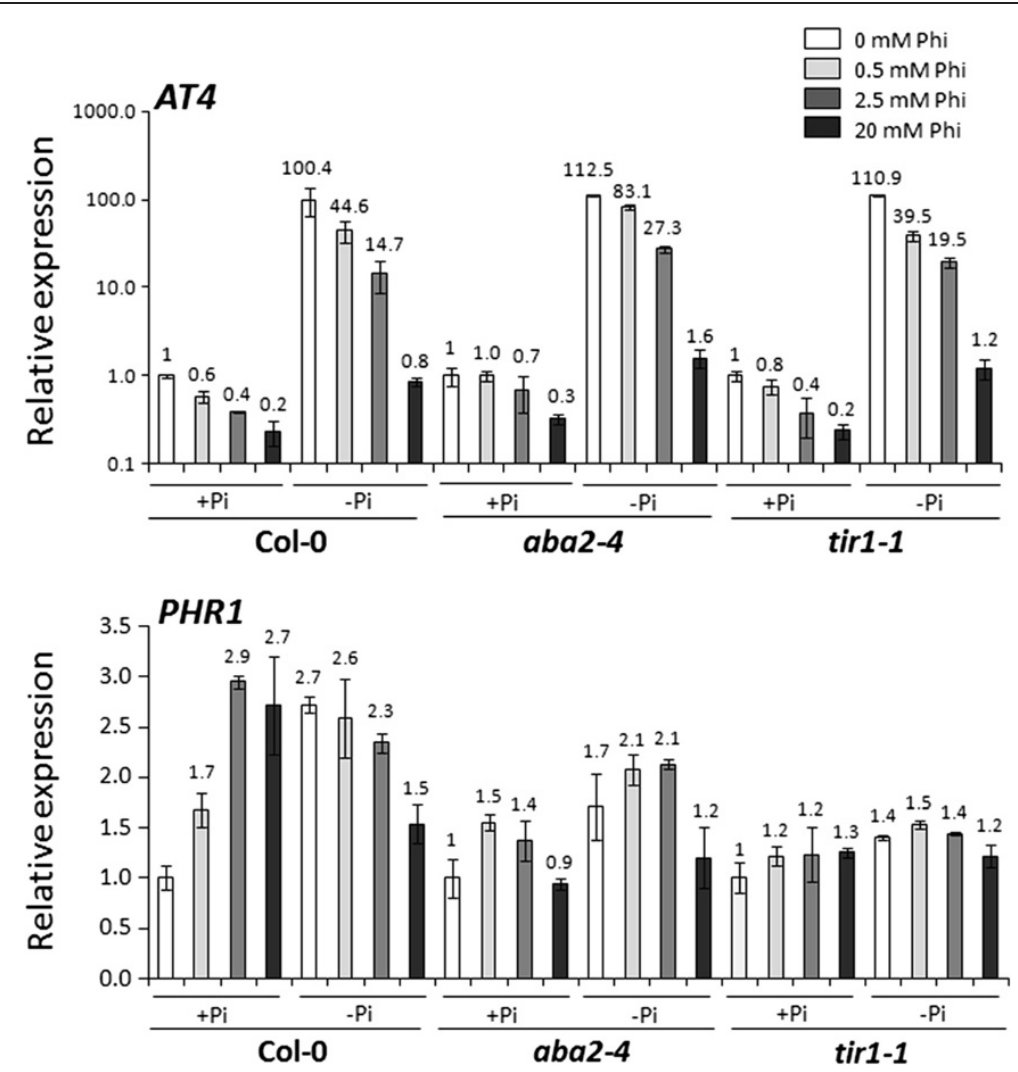

Figure 3 Effect of phosphite on phosphate starvation responsive genes in Col-0, aba2-4 and tir1-1. Relative expression ratios of AT4 and PHR1 transcripts in Arabidopsis thaliana wild ecotype (Col-0) and Arabidopsis mutants aba2-4 and tir $1-1$ grown in phosphate (Pi) sufficient media $(1.25 \mathrm{mM})$ for three weeks followed by a further five days growth in different $\mathrm{Pi}(1.25 \mathrm{mM} \mathrm{Pi}$; $\mathrm{Pi}$ and $0 \mathrm{mM} \mathrm{Pi}$; $-\mathrm{Pi})$ and phosphite (Phi) $(0,0.5,2.5$ and $20 \mathrm{mM}$ ) levels. The transcript levels in the mutant were normalized based on the expression of actin 2 (ACT2) measured in the same samples and presented relative to the normalized expression levels in non-Phi treated, Pi-sufficient grown Col-0. Bars present the mean and standard error from four replicates each consisting of three plants. The numbers on each bar indicate the fold change in gene transcript levels relative to corresponding Pi sufficient (+Pi), non-Phi-treated plants. One way ANOVA indicated a significant $(P<0.001)$ difference between genotypes. LSD (5\%) for AT4 and PHR1 were 23.96 and 1.01 , respectively.

in Pi deficient plants (Figure 4). In Pi sufficient Col-0, Phi treatments $(2.5$ and $20 \mathrm{mM})$ induced significantly $(P<0.05)$ the transcript levels of $A U X 1, A X R 1, A X R 2$ and $S G T 1 B$ genes and the level of this induction depended on the Phi concentrations used (Figure 4). Addition of Phi to Pi starved plants at $0.5 \mathrm{mM}$ suppressed the enhanced transcript level of AUX1 (from 2.3-fold to 1.1-fold); while, Phi treatments at $0.5 \mathrm{mM}$ had no significant $(P>0.05)$ effect on the expression of $A X R 1, A X R 2$ and $S G T 1 B$ in Pi deficient Col-0 (Figure 4). However, application of Phi at higher concentrations (2.5 and $20 \mathrm{mM}$ ) to $\mathrm{Pi}$ starved plants had no significant $(P>0.05)$ effect on the expression of $A U X 1, A X R 1, A X R 2$ and SGT1B genes (Figure 4).

In Pi deficient, non-Phi-treated aba2-4 mutant, the transcript levels of $A U X 1, A X R 1, A X R 2$ and $S G T 1 B$ genes did not increase significantly $(P>0.05)$ compared to that in the Pi sufficient, non-Phi-treated aba2-4 mutant (Figure 4) suggesting that PSR- responsive expression of the auxin responsive genes is reliant on ABA signalling. Furthermore, application of Phi to the aba2-4 mutant grown under either Pi sufficient or Pi deficient conditions did not increase transcript level of auxin responsive genes (AUX1, AXR1, AXR2 and SGT1B) with the exception of $0.5 \mathrm{mM}$ Phi-treated plants for the AXR1 gene (Figure 4). These results suggest that the Phi-mediated activation of auxin responsive genes may involve ABA signalling. In the tir1-1 mutant, Pi starvation did not considerably change the transcription levels of the auxin responsive genes $A U X 1, A X R 1, A X R 2$ and $S G T 1 B$ confirming a role for TIR1 in induction of the PSR. Furthermore, application of Phi in Pi sufficient or deficient conditions to tirl-1 did not affect the transcript levels of the auxin responsive genes tested with the exception of $A X R 1$ in $0.5 \mathrm{mM}$ Phi-treated, Pi deficient plants (Figure 4). The results indicate that $A B A 2$ is to some extent required for both PSR induced auxin responsive genes and Phi induced auxin responsive gene expression. Likewise, TIR1 is required for both PSR and 


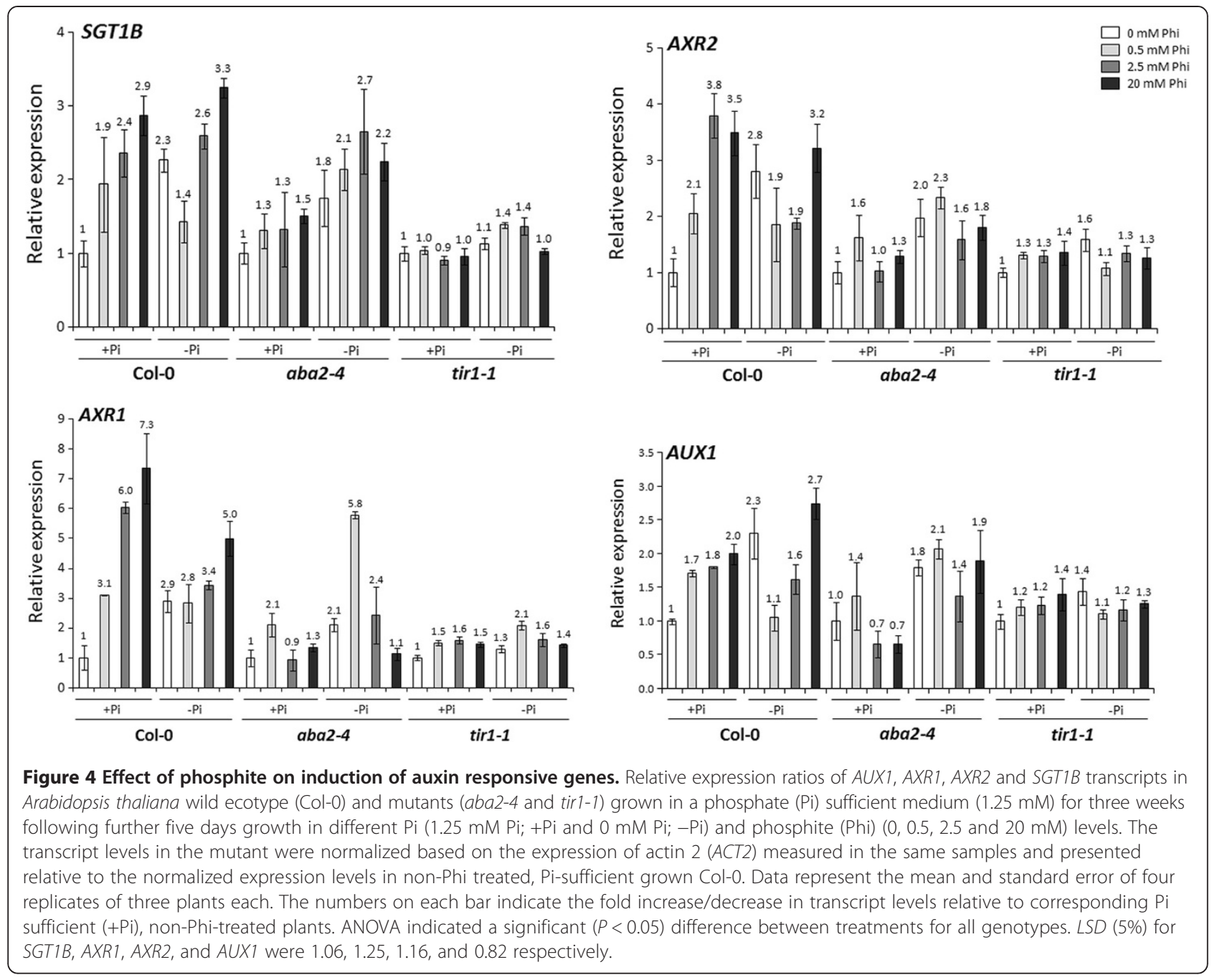

Phi mediated auxin responsive gene expression, suggesting that Phi may act through mechanisms involving both $\mathrm{ABA}$ and auxin.

\section{Effects of Phi treatment on auxin-mediated root architecture}

Given the potential of Phi to mimic the PSR in terms of auxin responsive gene expression, the potential for Phi to interfere with morphological responses of plant roots to Pi starvation was investigated.

The primary root length of Pi starved Col-0 seedlings was significantly $(P<0.05)$ shorter than that in seedlings grown in Pi sufficient media (Figure 5A). Application of Phi resulted in suppression of primary root growth in seedlings grown in Pi sufficient media and the level of this suppression depended on the Phi concentrations used (Figure 5A). Pi starvation induced root hair formation in non-Phi treated seedlings compared to that observed in Pi sufficient grown Col-0 seedlings (Figure 5B, C). Furthermore, treatment of seedlings with a low concentration of Phi $(2.5 \mathrm{mM})$ resulted in suppression of root hair formation in Pi sufficient grown seedlings, while in $20 \mathrm{mM}$ Phi-treated seedlings root hair density was increased (Figure 5B,C). Phi at both $2.5 \mathrm{mM}$ and $20 \mathrm{mM}$ concentrations inhibited root hair formation induced by Pi starvation.

\section{Discussion}

The findings of this study supported the role of auxin signalling in the induction of resistance to the predominantly necrotrophic pathogen $P$. cinnamomi. We further illustrate the effect of Phi on Pi signalling and the importance of their concomitant effect on activation/ suppression of the auxin response pathway in relation to PSR.

\section{Phosphate starvation response mutant showed susceptibility to $P$. cinnamomi}

The involvement of Phi in resistance to $P$. cinnamomi [53] and its interference in the phosphate starvation 


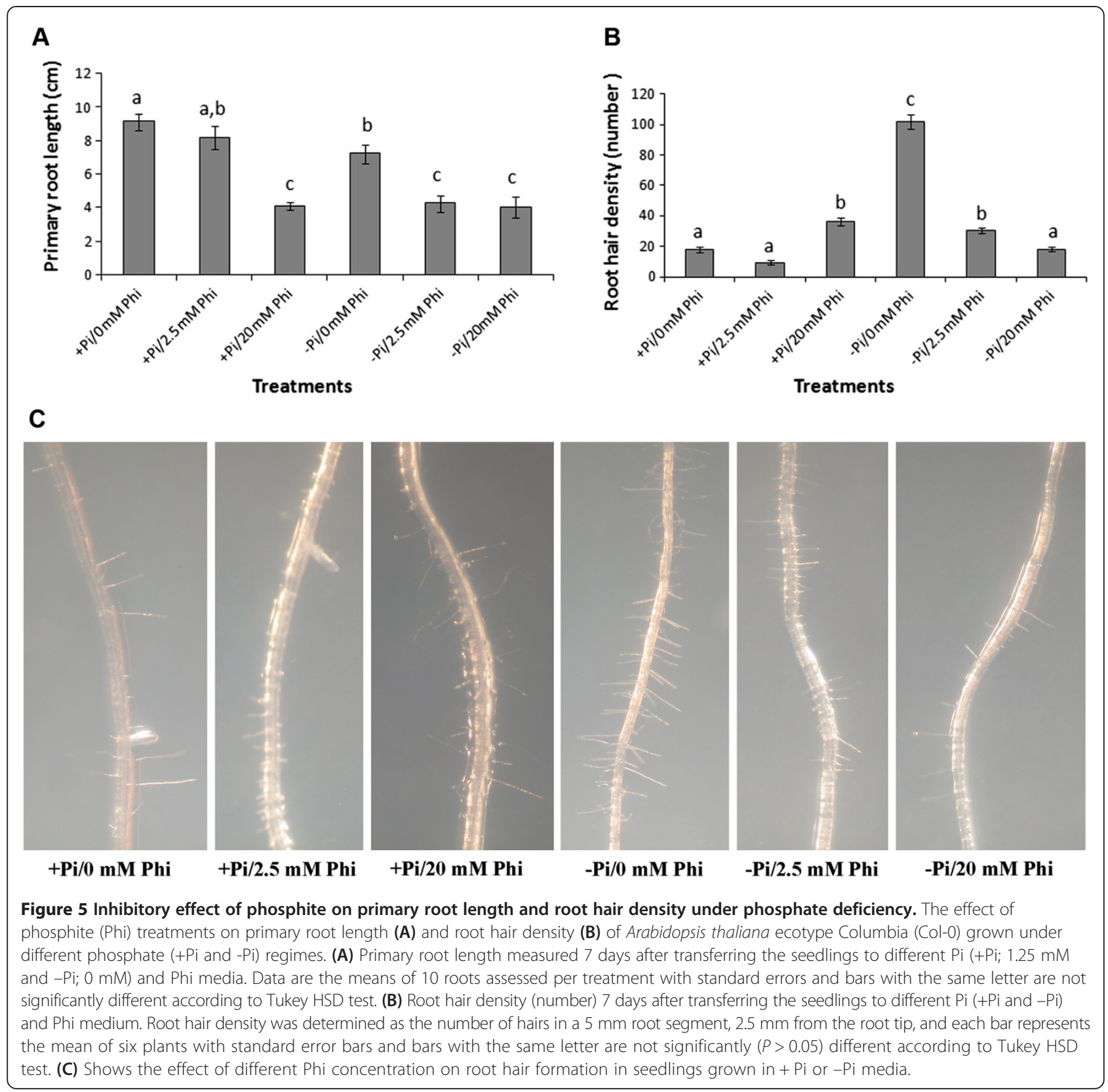

responses $[15,54,55]$ suggested a possible role of Pi signalling in the outcome of $A$. thaliana-P. cinnamomi interactions. QPCR analysis of infection revealed that phr1-1, a mutant defective in response to Pi starvation was highly susceptible to $P$. cinnamomi; while, the mutants pho2-1 and pho1-2 remained resistant. The MYBlike transcription factor encoded by the PHOSPHATE STARVATION RESPONSE 1 (PHR1) is vital for adaptation to phosphate deficiency in Arabidopsis [56] and this gene contributes to downstream Pi signalling by regulating the expression of Pi-responsive genes [38-40]. The $\mathrm{PHO} 2$ in Arabidopsis is a sub-component of the $\mathrm{Pi}-$ signalling network that functions downstream of PHR1 and regulates a subset of Pi-dependent responses, including Pi allocation between the shoot and the root $[43,44]$. Thus, mutation in the PHR1 gene impairs many Pi signalling-related functions [38], while pho1 and pho2 mutations individually attenuate Pi uptake and distribution within tissues [57,58]. Up-regulation of $P H O 1$ is shown to be dependent on the PHR1 transcription factor $[41,42]$. Furthermore, the cross talk between Pi, ABA and auxin signal transduction pathways have been suggested by Ribot et al. [42] demonstrating that application of exogenous $\mathrm{ABA}$ and auxin down-regulates the expression of PHO1 independent of the plants' Pi status [42]. Therefore, mutation of PHR1 is likely to affect other Pi 
responses in addition to those dependent on PHO1 and $\mathrm{PHO} 2$ and the regulation of these responses, and resistance to $P$. cinnamomi, may be associated with ABA and/ or auxin signalling.

\section{Auxin response pathway is involved in $P$. cinnamomi resistance}

The phytohormone auxin, in addition to being involved in many aspects of development and growth in healthy plants [59-62], plays an important role in plant-pathogen interactions $[9,63]$. Together the role of the auxin (IAA) signalling pathway in the PSR [19], plant disease resistance [35] and the high susceptibility of phr1-1 observed in the present study suggested a possible involvement of auxin signalling in resistance to P. cinnamomi. The QPCR analysis of $P$. cinnamomi infection in inoculated leaves of Col-0 and auxin-related mutants showed that tir1-1, an auxin receptor mutant was highly susceptible to $P$. cinnamomi. An effective auxin response in Arabidopsis depends on the removal of AUX/IAA family of transcriptional factor (TF) repressors through auxinstimulated binding by the $\mathrm{SCF}^{\mathrm{TIR} 1}$ complex $[46,48]$ and the TIR1 protein acts as an auxin receptor which directly links auxin perception to degradation of the AUX/IAA repressor proteins. In Arabidopsis auxin response mutants, the defective degradation of AUX/IAA transcriptional repressor proteins affect the induction of Auxin Response Factors (ARFs) and consequently the expression of auxin responsive genes [64]. Therefore, the susceptibility of the tir1-1 mutant which is defective in the F-box TIR1 protein and AUX/IAA degradation [45-47] suggested that ubiquitin-mediated AUX/IAA protein degradation is important in plant resistance to $P$. cinnamomi.

TIBA (a polar auxin transport inhibitor) treatment also led to the enhanced susceptibility of lupin seedlings to $P$. cinnamomi suggesting that the suppression of auxin transporters and consequently distruption of auxin signalling is important in plant resistance to P. cinnamomi. Llorente et al. [35] also suggested the involvement of the auxin signalling pathway in resistance to necrotrophic pathogens by demonstrating that the suppression of the auxin response pathway enhanced the susceptibility of Arabidopsis to Botrytis cinerea and Plectosphaerella cucumerina.

In Arabidopsis, SGT1B contributes to the auxin response controlled by the SCF ${ }^{\mathrm{TIR} 1}$ complex [30,45], through SCF-TIR1 mediated degradation of AUX/IAA repressor proteins [29-31]. SGT1B also functions in $R$ gene mediated plant disease resistance signalling and in this regard interacts with RAR1 [29,33]. When challenged with $P$. cinnamomi the sgt1b-1 mutant showed no significant $(P>0.05)$ difference to its parental background Col-0, suggesting that SGT1B contributes a redundant role to resistance to $P$. cinnamomi. Together the susceptibility of tir1-1, the enhanced susceptibility of TIBA-treated plants and the resistance of $s g t 1 b-1$ indicated that auxin plays a substantial role in resistance to $P$. cinnamomi through a $\mathrm{SCF}^{\mathrm{TIR} 1}$-mediated ubiquitination mechanisim that is independent to SGT1B function.

\section{Involvement of $26 \mathrm{~S}$ proteasome in $A$. thaliana- $P$. cinnamomi interaction}

The 26S proteasome is involved in the ubiquitination of AUX/IAA proteins and consequently activation of auxin responsive genes [49], and mutants that are compromised in $26 \mathrm{~S}$ proteasome activity attenuate auxin sensitivity and other plant processes such as root apical meristems maintenance, leaf organ size and gametophyte developments [28,65-68]. In the present study, several Arabidopsis mutants defective in $26 \mathrm{~S}$ proteasome subunits (pbe1, rpt $2 a, \mathrm{r} p t 2 b, r p t 5 a$ and $r p n 10)$ were screened for their susceptibility to $P$. cinnamomi. The analysis of pathogen infection revealed that pbe1, a $20 \mathrm{~S}$ proteasome knockout mutant was highly susceptible to P. cinnamomi in comparison to its parental background Col-0. In addition, the rpn10 mutant, defective in ubiquitin/26S proteasome-mediated proteolysis in auxin and ABA signalling, was susceptible to $P$. cinnamomi. RPN10 is a subunit of the $26 \mathrm{~S}$ proteasome pathway which affects several regulatory processes in Arabidopsis by directing the unwanted proteins to the $26 \mathrm{~S}$ proteasome for degradation [51]. The Arabidopsis rpn10 mutant shows a decreased sensitivity to auxin and is highly sensitive to exogenous application of ABA [51]. The reduction in auxin sensitivity in rpn10 may relate to its susceptibility to $P$. cinnamomi and further supports a role for TIR1/26S proteosome in resistance to $P$. cinnamomi.

Furthermore, Arabidopsis $26 \mathrm{~S}$ proteasome subunit mutants $r p t 5 a, r p t 2 a$ and $r p t 2 b$ (homologue of $r p t 2 a$ ) also showed a higher level of susceptibility compared to that observed in their parental background Col-0. The susceptibility of the mutants defective in $26 \mathrm{~S}$ proteasome subunits to $P$. cinnamomi suggested a role of $26 \mathrm{~S}$ proteasome subunits in resistance to $P$. cinnamomi, possibly through degradation of auxin inhibitor proteins following their ubiquitination by TIR1.

\section{Concomitant effect of Phi and $\mathrm{Pi}$ is relevant for the activation/suppression of PSR- and auxin-related genes}

The role of Phi in induction of resistance to Phytophthora has been demonstrated in several studies suggesting its complex mode of action including (i) acting directly by inhibition of pathogen growth, (ii) acting indirectly by inducing the release of stress metabolites from the pathogen to elicit the defence response and (iii) indirectly stimulating host defence responses [53,69-72]. Eshraghi et al. [53] found that Phi mediated resistance to $P$. cinnamomi in the susceptible Arabidopsis ecotype 
Ler resembled the response of the resistant ecotype Col-0 in terms of timing and the defence responses induced. Similar observations for Phi mediated resistance were reported for $P$. infestans-challenged potato [73] and $P$. palmivora-challenged $A$. thaliana [71]. Previous research demonstrated that Phi primed some aspects of the defence response, such as the expression of defence genes involved in the SA, JA/ET pathways in the absence of a pathogen $[53,71,73]$. However, screening SA and JA/ET related knockout mutants in the presence/absence of Phi suggested that Phi mediated resistance to P. cinnamomi in A. thaliana was independent of the SA, JA or ET signalling pathways [52].

Phi has also been shown to interfere with a broad range of biochemical and developmental responses including PSR in plants [15-18] many of which have been shown to rely on auxin signalling involving the $\mathrm{SCF}^{\mathrm{TIR} 1}$ UPP complex [19-21]. The susceptibility of Arabidopsis auxin response pathway mutants and the Pi response mutant phr-1 to $P$. cinnamomi in this study together with the interference of Phi in Pi homeostasis and its role in the induction of plant defence responses against $P$. cinnamomi [53] suggested that Phi mediated resistance could be through its' effect on Pi signalling, and in particular, on the auxin signalling pathway.

The transcript levels of the PSR responsive genes AtPT2, AtACP5, and AT4 increased in response to Pi deficiency. However, Phi applications at all levels suppressed their enhanced expression similar to that observed in plants grown in Pi sufficient media, demonstrating the effect of Phi in suppression of PSR. These results are supported by Ticconi et al. [54] who reported a similar effect of Phi on suppression of PSR genes. While PHR1 expression was increased by Phi treatment of Col-0 under Pi sufficient conditions, similar increases in expression of AtPT2, AtACP5 and AT4 were not observed. This may be because PHR1 contributes to downstream Pi signalling by regulating the expression of $\mathrm{Pi}$ responsive genes [38,40] and PHO1 and PHO2 both act downstream of the PHR1 transcription factor to control the local uptake or Pi allocation between the shoot and the root involving AtPT2, AT4 and AtACP5 [41,44,74]. Although the mutation in the PHR1 gene impairs many Pi signalling-related functions, the studies by Ribot et al. [42] suggested that the expression of PHO1 is independent of the plants' $\mathrm{Pi}$ status. Therefore, PHR1 is likely to affect other Pi responses in addition to those dependent on PHO1 and PHO2 and the regulation of these responses.

Perez-Torres et al. [25] demonstrated that auxin sensitivity was enhanced in $\mathrm{Pi}$ deficient Arabidopsis plants largely through increased expression of TIR1, which accelerated the degradation of AUX/IAA proteins. In addition to the potential interaction with PSR/auxin signalling described above, Eshraghi et al. [52] suggested that Phi acts partially through an ABA dependent mechanism. Therefore, to investigate whether Phi acts through TIR1 or $A B A 2$ and whether mutations in these two genes are affecting the impact of Phi on PSR, the effect of Phi on expression of AT4 and PHR1 at the transcriptional level was further tested in Pi sufficient and Pi deficient grown Col-0, aba2-4 and tir1-1. Although in Col-0 Phi treatments suppressed the enhanced transcript levels of PHR1 induced by Pi deficiency, Phi enhanced the transcript levels of PHR1 in Pi sufficient grown samples and the level of this induction depended on the Phi concentrations used. These results suggested that although Phi suppressed the PSR in Pi starved plants, application of Phi to Pi sufficient plants resulted in activation of PSR. One explanation for this may be competition between $\mathrm{Pi}$ and Phi for uptake or transport. It has been shown in Brassica spp. that high Phi concentrations inhibit plant development by competing with Pi absorption [75,76]. Our results showed that the expression of PHR1 in response to Pi starvation was affected in the aba2-4 and tir1-1 mutants suggesting the importance of $A B A 2$ and TIR1 genes in the induction of PHR1 and PSR. Furthermore, Phi treatments had no considerable effect on transcript level of the PHR1 gene in either aba2-4 or tir1-1 mutants suggesting that mutation in the $A B A 2$ and TIR1 genes may disrupt the Phi effect on Pi signalling.

The induction of the PHR1 gene by Phi in Col-0 samples grown in Pi sufficient media suggested that Phi induces PSR and the loss of PHR1 gene expression in the tir1-1 mutant highlighted the possible induction of the auxin response pathway by Phi treatments. To test this further, the concomitant effect of Phi and Pi on auxin signalling in $\mathrm{Pi}$ sufficient/Pi deficient grown Col-0, aba2-4 and tir1-1 mutants was assessed by measuring the relative expression ratios of the auxin responsive genes, AUX1, AXR1, AXR2 and SGT1B transcripts. Pi deficiency increased the transcript levels of all genes tested suggesting the induction of the auxin response pathway in Pi starved plants. In Pi sufficient Col-0, Phi treatments $(2.5$ and $20 \mathrm{mM})$ induced the transcript levels of AUX1, AXR1, AXR2 and SGT1B and the level of this induction depended on the Phi concentrations used. Moreover, Pi starvation did not considerably change the transcription levels of the auxin responsive gene AUX1, AXR1, AXR2 and SGT1B in the aba2-4 and tir1-1 mutants confirming a role for $A B A 2$ and TIR1 in the induction of the PSR. Overall, the results suggested that $A B A 2$ and TIR1 genes are required for both PSR and Phi mediated auxin responsive gene expression, indicating that Phi may act through both the ABA and auxin pathways.

\section{Effect of Phi on root morphology}

Considering the potential of Phi to mimic the PSR in terms of auxin responsive gene expression, the effect on 
morphological responses to $\mathrm{Pi}$ starvation was investigated, as Pi status acting through auxin signalling is important for determining root architecture [19-21]. Pi deficiency suppressed the primary root length and induced root hair formation in roots of ecotype Col- 0 and the application of Phi resulted in suppression of primary root growth in seedlings grown in either Pi sufficient or Pi deficient media in a dose-response manner. The morphological responses of Pi starved roots were consistent with those previously described [20,21,77-79]. Phi at lower concentration $(\leq 2.5 \mathrm{mM})$ inhibited root hair formation induced under phosphate starvation; however, $20 \mathrm{mM}$ Phi induced root hair formation in Pi sufficient plants. Gilbert et al. [80] also showed that Phi dramatically increased the number of proteoid root segments (a phosphate starvation response) in Pi sufficient lupin seedlings. Overall, both, morphological and gene expression data suggested the involvement of the auxin signaling pathway and phosphate signalling in responses to Phi treatment.

\section{Conclusions}

This study highlighted the importance of Pi signalling in plant resistance to $P$. cinnamomi by illustrating the susceptibility of phr1-1 (a mutant defective in Pi signalling) and linked this role with the auxin response pathway through the susceptibility of tir1-1 and TIBA-treated plants to $P$. cinnamomi. A role for the $26 \mathrm{~S}$ proteasome, which is required for auxin signalling $[28,49]$, was further supported by the susceptibility of lines with mutations in various components. Moreover, the link between Phi treatment and PSR, as demonstrated by morphological PSR responses and analysis of Pi starvation gene expression following Phi treatment under Pi sufficient and deficient conditions and in auxin and ABA response mutants, suggested that the mechanism of action of Phi may include modulation of Pi signalling involving auxin.

\section{Methods}

\section{Plant and pathogen materials}

Arabidopsis thaliana accession Columbia (Col-0) and several $A$. thaliana mutant/transgenic lines (Table 2) in the Col-0 background that are defective in different signalling pathways were used in this study. Arabidopsis thaliana genotype Col-0 was purchased from LEHLE Seeds (Round Rock, TX), and the mutants rpt $2 a, r p t 5 a$, rpn10, and cni1 were provided by Dr Derek Gotto and Prof. Junji Yamaguchi (Hokkaido University, Japan). The remaining mutants were obtained from the Arabidopsis Biological Resource Centre (ABRC, Ohio State University); https://abrc.osu.edu/. Blue lupin (L. angustifolius L., cv. Mandalup) seeds were obtained from Department of Agriculture and Food, Western Australia (DAFWA).
Phytophthora cinnamomi (isolate MP 94.48) was obtained from the Centre for Phytophthora Science and Management (CPSM) at Murdoch University. Phytophthora cinnamomi zoospores were produced aseptically according to the method described by Byrt \& Grant [81], and the zoospores density was determined using a bright line haemocytometer and adjusted to a concentration of $1 \times 10^{5}$ zoospores $\mathrm{mL}^{-1}$ using sterile distilled water.

\section{Plant growth conditions and inoculation procedure}

Arabidopsis thaliana ecotype Col-0 and mutants were germinated on half strength Gamborg's B-5 Basal medium with $0.8 \%(\mathrm{w} v)$ phytagar [82]. In addition, $2.5 \mathrm{mM} \mathrm{MES}$ [2-(N-morpholino)-ethanesulphonic acid]-KOH ( $\mathrm{pH}$ 5.7) and $0.5 \%(\mathrm{wV})$ sucrose were included $(\mathrm{pH} 5.7$, adjusted with $\mathrm{KOH}$ ). After sowing the seed on the medium, seeds were stratified for 3 days at $4^{\circ} \mathrm{C}$ in the dark before being transferred to a growth cabinet at $21^{\circ} \mathrm{C} \pm 1^{\circ} \mathrm{C}$ with a 10 -h photoperiod at a photon fluorescence rate of $100 \mu \mathrm{mol} \mathrm{m} \mathrm{m}^{-2} \mathrm{~s}^{-1}$. To study A. thaliana-P. cinnamomi interactions, attached leaves of four-week-old seedlings were inoculated either with $3 \mu \mathrm{L}$ of $1 \times 10^{5}$ P. cinnamomi zoospores $\mathrm{mL}^{-1}$ or $3 \mu \mathrm{L}$ of sterile distilled water (control) on the abaxial surface. Five samples per genotype were collected $72 \mathrm{~h}$ after inoculation for quantitative PCR (QPCR) analysis of infection and the experiment was conducted twice.

The lupin (Lupinus angustifolius L., cv. Mandalup) seeds were surface-sterilized in $70 \%$ ethanol for $2 \mathrm{~min}$ followed by immersion in $50 \%$ bleach solution $(6.25 \%$ available chlorine) for $5 \mathrm{~min}$. The sterilized seeds were germinated on sterile filter paper pre-moistened with distilled water at $25^{\circ} \mathrm{C}$ in the dark for 3 days. The seedlings were placed on a bed of damp absorbent paper $(24 \times 38.5 \mathrm{~cm})$, placed between two layers of clear plastic, rolled up and placed in $200 \mathrm{~mL}$ beakers filled with $50 \mathrm{~mL}$ half-strength hydroponic Hoagland medium [83] and grown for a further five days in a growth cabinet with a $10-\mathrm{h}$ photoperiod $\left(100 \mu \mathrm{mol} \mathrm{m}^{-2} \mathrm{~s}^{-1}\right.$ at $21 \pm$ $1^{\circ} \mathrm{C}$ ) until treatments. Lupin seedlings were inoculated by placing a $4 \mathrm{~mm}$ diameter plug of $P$. cinnamomi mycelium at the tips of roots. Root tissue samples were collected for lesion size assessments at $48 \mathrm{~h}$ and $72 \mathrm{~h}$ after inoculation.

\section{Quantitative PCR analysis of infection}

To determine the level of infection quantitatively, QPCR analysis was conducted and the relative amount of $P$. cinnamomi biomass (DNA) in infected Arabidopsis leaf samples was measured and normalized based on plasmid DNA (internal control) according to Eshraghi et al. [37]. Samples were collected and snap frozen $72 \mathrm{~h}$ after inoculation. Five samples per treatment each containing 
Table 2 The list of Arabidopsis mutant/transgenic lines used in this study

\begin{tabular}{|c|c|c|c|c|}
\hline Name & Locus & Genetic alteration & Phenotypes & References \\
\hline$a b a 2-4$ & AT1G52340 & EMS mutant & Defective in ABA biosynthesis, reduced sensitivity to sugar and glucose & [86] \\
\hline phr1-1 & AT4G28610 & T-DNA-insertion & Defective in response to phosphate $(\mathrm{Pi})$ starvation & {$[74,87]$} \\
\hline pho1-2 & AT3G23430 & EMS mutant & Decreased Pi level in shoot, but normal Pi level in root & [88] \\
\hline pho2-1 & AT2G33770 & EMS mutant & Pi over-accumulator and exhibits increased levels of $\mathrm{Pi}$ in the shoots & [89] \\
\hline tirl-1 & AT3G62980 & EMS mutant & Defective in auxin response & [90] \\
\hline sgt1b-1 & AT4G11260 & EMS mutant & Defective in $\mathrm{SCF}^{\mathrm{TTR} 1}$ mediated auxin response & [30] \\
\hline pbel & AT1G13060 & T-DNA-insertion & A knockout mutant for 205 proteasome & {$[50]$} \\
\hline rpt2a & AT4G29040 & T-DNA-insertion & Defective in 265 proteasome subunit & {$[65,68,91]$} \\
\hline$r p t 2 b$ & AT2G20140 & T-DNA-insertion & Defective in 265 Proteasome Subunit & {$[65,91]$} \\
\hline rpt5a & AT3G05530 & T-DNA-insertion & Defective in 265 Proteasome Subunits & [68] \\
\hline $\operatorname{rpn} 10$ & AT4G38630 & T-DNA-insertion & $\begin{array}{l}\text { Defective in ubiquitin/26S proteasome-mediated proteolysis (UPP) substrate } \\
\text { recognition and in abscisic acid signalling }\end{array}$ & {$[51,92]$} \\
\hline
\end{tabular}

All lines mentioned are in the Col-0 background.

four leaf discs (7 $\mathrm{mm}$ in diameter) from one seedling were collected.

\section{TIBA treatments and lesion size assessments in lupin}

The auxin transport inhibitor TIBA (2, 3, 5-triiodobenzoic acid; Sigma Aldrich) was dissolved in absolute ethanol and filter sterilised TIBA was added to sterilized half-strength liquid Hoagland medium to give a final concentration of $10 \mu \mathrm{M}$. TIBA treatment was conducted on five-day-old lupin seedlings by transferring the seedlings to halfstrength hydroponic Hoagland medium containing $10 \mu \mathrm{M}$ TIBA (+TIBA). For controls (-TIBA), the seedlings were transferred to the half-strength hydroponic Hoagland medium with the same amount of ethanol as in + TIBA medium. $48 \mathrm{~h}$ after treatments, the roots were inoculated by placing a $4 \mathrm{~mm}$ diameter plug of $P$. cinnamomi mycelium at the root tips and seedlings were kept in halfstrength hydroponic Hoagland medium until harvested.

A minimum of 10 lupin roots per treatment were assessed for lesion development and the experiment was repeated twice. The level of infection was measured 48 and $72 \mathrm{~h}$ after $P$. cinnamomi inoculation and the data were presented as mean percentage infected root area. The digital images of the roots were captured with as Epson Expression 1680 scanner and the area of lesions formed by $P$. cinnamomi infection were calculated using the program WinRHIZO ${ }^{\mathrm{mm}}$ (Régents Instruments, Inc.).

\section{Cloning PHR1 and TIR1}

In order to restore function of PHR 1 and TIR 1 genes in phr1-1 and tir1-1 knock out mutants, these gene were cloned and transferred to the knock out mutants as follow. Col-0 genomic DNA was used as template for cloning PHR1 gene (AT4G28610) and TIR1gene (AT3G62980). PCR was performed with Phusion ${ }^{\circledR}$ High-Fidelity DNA Polymerase (BioLabs) according to manufacturer's instructions using primers containing the attB recombination sites (PHR1-forward 5'- GGG GAC AAG TTT GTA CAA AAA AGC AGG CT T CTC TTC CTT GGT CCT GGA TTG and PHR1-reverse 5'GGG GAC CAC TTT GTA CAA GAA AGC TGG GTC TCT TCC TTG GGG ATC TGT TG, TIR1-forward 5'-GGG GAC AAG TTT GTA CAA AAA AGC AGG CTT CCG CTG TCC AAC TTC TTC CTC and TIR1reverse $5^{\prime}-\mathrm{GG} \mathrm{G}$ GAC CAC TTT GTA CAA GAA AGC TGG GTC GTT CCT AAA CCG GAA CAC GA. The PCR products were cloned to pDONR207 (Invitrogen) using Gateway ${ }^{\bullet}$ BP Clonase ${ }^{\bullet}$ II Enzyme Mix (Invitrogen) according to the manufacturer's instructions and transformed into $E$. coli competent cells (DH5 $\alpha$ ). After confirmation by sequencing, the insert was cloned into the Gateway $^{\oplus}$ compatible expression vector pGREEN0179 containing CAMV 2x35S promoter and CAMV terminator with a Gateway A cassette [84] using Gateway ${ }^{\circ}$ LR Clonase $^{\oplus}$ II enzyme mix (Invitrogen) according to manufacturer's instructions. Positive clones were confirmed by PCR and phr1-1, and tir1-1 mutants were transformed using Agrobacterium tumefaciens C58C1 (pCH32) [85].

\section{Quantitative measurements of gene transcription using qRT-PCR}

For quantitative measurement of gene transcription, seeds of ecotype Col-0 and the A. thaliana mutants aba2-4 and tir1-1 were germinated on half strength $0.8 \%$ (W/V) phytagar-Gamborg B-5 basal medium ( $\mathrm{pH}$ 5.7) as previously described. The seedlings were grown in a growth cabinet at $21 \pm 1^{\circ} \mathrm{C}$ with a 10 -h photoperiod at a photon fluorescence rate of $100 \mu \mathrm{mol} \mathrm{m} \mathrm{m}^{-2} \mathrm{~s}^{-1}$ for three weeks and then transferred to half strength $0.8 \%(\mathrm{~W} / \mathrm{V})$ phytagar-Hoagland medium [83] $(\mathrm{pH}$ 5.7, adjusted with $\mathrm{KOH}$ ) with different concentrations of $\mathrm{Pi}(0$ and $1.25 \mathrm{mM})$ and Phi $(0,0.5,2.5$ and $20 \mathrm{mM})$ in a 
completely randomized design and grown for a further five days. A stock solution of filter sterilized potassium Phi ( $\mathrm{pH} 5.7$, adjusted with $\mathrm{KOH}$ ) was freshly prepared from phosphorous acid (Aldrich Chemicals) and mixed with sterilized medium to give the specified Phi concentration. Samples were collected, frozen in liquid nitrogen and stored at $-80^{\circ} \mathrm{C}$ until RNA extraction and qRT-PCR.

Four biological samples per treatment were randomly collected for gene expression analysis and each sample was a pool of three plants. Tissue samples were homogenized using Tissuelyser (Qiagen, Inc.) and the RNeasy plant mini kit (Qiagen, Inc.) was used to isolate RNA according to the manufacturer's instructions. Approximately, $3 \mu \mathrm{g}$ of DNA-free RNA was used for first-strand cDNA synthesis using the SuperScript III First-Strand Synthesis System for RT-PCR (Invitrogen). Gene specific primers (Additional file 1: Table S1) were designed using Primer Express 1.5 software (Applied Biosystems Inc.) and qRT-PCR conducted according to [53]. The transcript levels of all genes in the mutants were normalized based on expression of actin 2 (ACT2) measured in the same samples and presented relative to the normalized expression levels in corresponding $\mathrm{Pi}$ sufficient, nonPhi-treated plants as fold expression.

\section{Root morphology assessments}

For morphological assessments of A. thaliana roots, seeds of ecotype Col-0 were grown on half strength Gamborg B-5 basal medium with 0.8\% (W/V) phytagar (pH 5.7) as previously described. One-week-old seedlings were transferred to half strength Hoagland medium with $0.8 \%(\mathrm{~W} / \mathrm{V})$ phytagar [83] ( $\mathrm{pH}$ 5.7) with different concentrations of $\mathrm{Pi}(0$ and $1.25 \mathrm{mM})$ and Phi $(0,2.5$ and $20 \mathrm{mM}$ ) in a completely randomized design and grown for further seven days. A minimum of 10 seedlings per treatment were assessed for their primary root growth using the photographs taken by a digital camera (Nikon; Cool PIX 995) and the experiment was repeated twice. A minimum of six seedlings per treatment were assessed for their root hair density using the photographs taken by a binocular microscope (Olympus SZ40) with an attached digital camera (Nikon; Cool PIX 995) and the experiment was repeated twice. Root hair density was determined as the number of hairs in a $5 \mathrm{~mm}$ root segment (from the root tip).

\section{Data analysis}

ANOVA was used in all measurements to compare the treatments and the normality of residuals was tested using GenStat software (14th edition). 5\% least significant difference (LSD) was calculated for the mean comparisons of treatments and genotypes using GenStat software (14th edition).

\section{Additional file}

Additional file 1: Table S1. Sequences of the gene-specific primer pairs used in quantitative real-time reverse transcription polymerase chain reaction (qRT-PCR) experiments.

\section{Abbreviations}

PSR: Phosphate starvation response; ABA: Abscisic acid; SA: Salicylic acid; JA: Jasmonic acid; ET: Ethylene; IAA: Indole-3-acetic acid; TIBA: 2, 3, 5-triiodobenzoic acid; UPP: Ubiquitin proteasome pathway; qRT-PCR: Quantitative reverse transcription polymerase chain reaction; QPCR: Quantitative real-time polymerase chain reaction.

\section{Competing interests}

The authors declare that they have no competing interests.

\section{Authors' contributions}

LE carried out the experimental designs, disease assessments, gene expression studies, cloning, transformations, data analysis, and drafted the manuscript. JA and NA participated in the design of the gene expression experiments, disease screening assessments, and involved in the interpretation of data and revising the manuscript. JM and BS participated in the design of disease assessment assays and revising the manuscript. GH coordinated the study and involved in interpretation of disease assessments and critically revising the manuscript. All authors read and approved the final manuscript.

\section{Acknowledgements}

We thank the Australian Commonwealth Government for providing an International Postgraduate Research Scholarship (IPRS) and Murdoch University Research Scholarship (MURS). We also thank the ABRC (Columbus, $\mathrm{OH}$ ) for providing the majority of the mutant lines tested in this study.

\section{Author details}

${ }^{1}$ Centre for Phytophthora Science and Management, School of Veterinary and Life Sciences, Murdoch University, South Street, Murdoch, WA 6150, Australia. ${ }^{2}$ CSIRO Plant Industry, Centre for Environment and Life Sciences, Private Bag 5, Wembley, WA 6913, Australia. ${ }^{3}$ School of Plant Biology, Faculty of Science, The University of Western Australia, 35 Stirling Highway, Crawley, WA 6009, Australia. ${ }^{4}$ The University of Western Australia, Institute of Agriculture, 35 Stirling Highway, Crawley, WA 6009, Australia. ${ }^{5}$ Science Division, Department of Environment and conservation, Kensington, WA 6983, Australia

Received: 17 December 2013 Accepted: 14 March 2014

Published: 20 March 2014

\section{References}

1. Brasier CM: The biosecurity threat to the UK and global environment from international trade in plants. Plant Pathol 2008, 57(5):792-808.

2. Hansen EM: Alien forest pathogens: Phytophthora species are changing world forests. Boreal Environ Res 2008, 13:33-41.

3. Shearer BL, Fairman RG: A stem injection of phosphite protects Banksia species and Eucalyptus marginata from Phytophthora cinnamomi for at least four years. Australas Plant Pathol 2007, 36(1):78-86.

4. Hardham AR: Pathogen profile: Phytophthora cinnamomi. Mol Plant Pathol 2005, 6:589-604.

5. Akinsanmi OA, Drenth A: Phosphite and metalaxyl rejuvenate macadamia trees in decline caused by Phytophthora cinnamomi. Crop Prot 2013, 53:29-36

6. Scanu BB, Linaldeddu BT, Franceschini A, Anselmi N, Vannini A, Vettraino AM: Occurrence of Phytophthora cinnamomi in cork oak forests in Italy. Forest Pathol 2013, 43:340-343.

7. Guest D, Grant B: The complex action of phosphonates as antifungal agents. Biol Rev Camb Philos Soc 1991, 66(2):159-187.

8. Hardy GESJ, Barrett S, Shearer BL: The future of phosphite as a fungicide to control the soilborne plant pathogen Phytophthora cinnamomi in natural ecosystems. Australas Plant Pathol 2001, 30(2):133-139.

9. Robert-Seilaniantz A, Grant M, Jones JDG: Hormone crosstalk in plant disease and defense: more than just jasmonate-salicylate antagonism. Annu Rev Phytopathol 2011, 49(26):317-343. 
10. Pozo MJ, Van Loon LC, Pieterse CMJ: Jasmonates-signals in plant-microbe interactions. J Plant Growth Regul 2005, 23(3):211-222.

11. Park JE, Park JY, Kim YS, Staswick PE, Jeon J: GH3-mediated auxin homeostasis links growth regulation with stress adaptation response in Arabidopsis. J Biol Chem 2007, 282:10036-10046.

12. Fan J, Hill L, Crooks C, Doerner P, Lamb C: Abscisic acid has a key role in modulating diverse plant-pathogen interactions. Plant Physiol 2009, 150:1750-1761.

13. De Torres ZM, Bennett MH, Truman WH, Grant MR: Antagonism between salicylic and abscisic acid reflects early host-pathogen conflict and moulds plant defence responses. Plant J 2009, 59:375-386.

14. Robert-Seilaniantz A, Maclean D, Jikumaru Y, Hill L, Yamaguchi S: The microRNA miR393 redirects secondary metabolite biosynthesis away from camalexin and towards glucosinolates. Plant J 2011, 67:218-231.

15. Lee TM, Tsai PF, Shyu YT, Sheu F: The effects of phosphite on phosphate starvation responses of Ulva lactuca (Ulvales, Chlorophyta). J Phycol 2005 41:975-982.

16. Ticconi CA, Delatorre CA, Lahner B, Salt DE, Abel S: Arabidopsis pdr2 revealed a phosphate-sensitive checkpoint in root development. Plant $J$ 2004, 37:801-814.

17. Li W-F, Perry PJ, Prafulla NN, Schmidt W: Ubiquitin-specific protease 14 (UBP14) is involved in root responses to phosphate deficiency in Arabidopsis. Mol Plant 2010, 3(1):212-223.

18. Fang Z, Shaob C, Menga Y, Wua P, Chen M: Phosphate signaling in Arabidopsis and Oryza sativa. Plant Sci 2009, 176(2):170-180.

19. Rietz S, Dermendjiev G, Oppermannb E, Tafesseb FG, Effendib Y, Holkb A Parkera JE, Teigec M, Schererb GFE: Roles of Arabidopsis patatin-related phospholipases a in root development are related to auxin responses and phosphate deficiency. Mol Plant 2010, 3(3):524-538.

20. Lo'pez-Bucio J, Herna'ndez-Abreu E, Sa'nchez-Caldero'n L, Nieto-Jacobo MF, Simpson J, Herrera-Estrella L: Phosphate availability alters architecture and causes changes in hormone sensitivity in the Arabidopsis root system. Plant Physiol 2002, 129:244-256.

21. Al-Ghazi Y, Muller B, Pinloche S, Tranbarger TJ, Nacry P, Rossignol M, Tardieu F, Doumas P: Temporal response of Arabidopsis root architecture to phosphate starvation: evidence for the involvement of auxin signalling. Plant Cell Environ 2003, 26:1053-1066.

22. Nacry P, Canivenc GV, Muller B, Azmi A, Van Onckelen H, Rossignol M Doumas $P$ : A role for auxin redistribution in the responses of the root system architecture to phosphate starvation in Arabidopsis. Plant Physiol 2005, 138:2061-2074.

23. Jain A, Poling MD, Karthikeyan AS, Blakeslee JJ, Peer WA, Titapiwatanakun B, Murphy AS, Raghothama KG: Differential effects of sucrose and auxin on localized phosphate deficiency-induced modulation of different traits of root system architecture in Arabidopsis. Plant Physiol 2007, 144:232-247.

24. Wooward AW, Bartel B: Auxin: regulation, action, and interaction. Ann Bot 2005, 95:707-735.

25. Perez-Torres C-A, Lopez-Bucio J, Cruz-Ramırez A, Ibarra-Laclette E, Dharmasiri S, Estelle M, Herrera-Estrella L: Phosphate availability alters lateral root development in Arabidopsis by modulating auxin sensitivity via a mechanism involving the TIR1 auxin receptor. Plant Cell 2008, 20:3258-3272.

26. $\mathrm{Yu}$ H, Moss BL, Jang SS, Prigge M, Klavins E, Nemhauser JL, Estelle M Mutations in the TIR1 auxin receptor that increase affinity for auxin/ Indole-3-Acetic Acid Proteins result in auxin hypersensitivity. Plant Physiol 2013, 162:295-303.

27. Schere GFE: AUXIN-BINDING-PROTEIN1, the second auxin receptor: what is the significance of a two-receptor concept in plant signal transduction? $J$ Exp Bot 2011, 62(10):3339-3357.

28. Smalle J, Vierstra RD: The ubiquitin $26 \mathrm{~S}$ proteasome proteolytic pathway. Annu Rev Plant Biol 2004, 55:555-590.

29. Austin MJ, Muskett P, Kahn K, Feys BJ, Jones JDG, Parker JE: Regulatory role of SGT1 in early $R$ gene-mediated plant defenses. Science 2077-2080, 2002:295.

30. Gray WM, Muskett PR, Chuang H-W, Parker JE: Arabidopsis SGT1b is required for SCF ${ }^{\text {TIR1 }}$-mediated auxin response. Plant Cell 2003, 15:1310-1319.

31. Tor M, Gordon P, Cuzick A, Eulgem T, Sinapidou E, Mert-Türk F, Can C, Dangl JL, Holub EB: Arabidopsis SGT1b is required for defense signaling conferred by several downy mildew resistance genes. Plant Cell 2002, 14:993-1003.

32. Dodds PN, Schwechheimer C: A breakdown in defense signaling. Plant Cell 2002, 14:5-8.
33. Azevedo C, Sadanandom A, Kitagawa K, Freialdenhoven S, Shirasu K, Schulze-Lefert P: The RAR1 interactor SGT1B, an essential component of $R$ gene-triggered disease resistance. Science 2073-2076, 2002:295.

34. Schwechheimer C, Serino G, Deng XW: Multiple ubiquitin ligasemediated processes require COP9 signalosome and AXR1 function. Plant Cell 2002, 14:2553-2563.

35. Llorente F, Muskett P, Sanchez-Vallet A, Lopez G, Ramos B, Sanchez-Rodriguez C, Jorda L, Parker J, Molina A: Repression of the auxin response pathway increases Arabidopsis susceptibility to necrotrophic fungi. Mol Plant 2008, 1(3):496-509.

36. Rookes JE, Wright ML, Cahill DM: Elucidation of defence responses and signaling pathways induced in Arabidopsis thaliana following challenge with Phytophthora cinnamomi. Physiol Mol Plant Pathol 2008, 72:151-161.

37. Eshraghi L, Aryamanesh N, Anderson JP, Shearer B, McComb JA, Hardy GESJ, O'Brien PA: A quantitative PCR assay for accurate in planta quantification of the necrotrophic pathogen Phytophthora cinnamomi. Eur J Plant Pathol 2011, 131:419-430.

38. Rubio V, Linhares F, Solano R, Martin AC, Iglesias J, Leyva A, Paz-Ares J: A conserved MYB transcription factor involved in phosphate starvation signaling both in vascular plants and in unicellular algae. Genes Dev 2001, 15:2122-2133

39. Sunkar R, Zhu J-K: Novel and stress-regulated microRNAs and other small RNAs from Arabidopsis. Plant Cell Environ 2001-2019, 2004:16.

40. Franco-Zorrilla JM, Gonzalez E, Bustos R, Linhares F, Leyva A, Paz-Ares J: The transcriptional control of plant responses to phosphate limitation. J Exp Bot 2004, 55:285-293.

41. Rouached H, Secco D, Arpat B, Poirier $Y$ : The transcription factor PHR1 plays a key role in the regulation of sulfate shoot-to-root flux upon phosphate starvation in Arabidopsis. BMC Plant Biol 2011, 11:1-19.

42. Ribot $C$, Wang $Y$, Poirier $Y$ : Expression analyses of three members of the AtPHO1 family reveal differential interactions between signaling pathways involved in phosphate deficiency and the responses to auxin, cytokinin, and abscisic acid. Planta 2008, 227:1025-1036.

43. Chiou TJ: The role of microRNAs in sensing nutrient stress. Plant Cell Environ 2007, 30(3):323-332.

44. Miura K, Rus A, Sharkhuu A, Yokoi S, Karthikeyan AS, Raghothama KG, Baek D, Koo YD, Jin JB, Bressan RA, Yun D-J, Hasegawa PM: The Arabidopsis SUMO E3 ligase SIZ1 controls phosphate deficiency responses. Proc Natl Acad Sci USA 2005, 102(21):7760-7765.

45. Gray WM, Kepinski S, Rouse D, Leyser O, Estelle M: Auxin regulates SCF ${ }^{\text {TIR1 }}$ dependent degradation of AUX/IAA proteins. Nature 2001, 414:271-276.

46. Dharmasiri N, Dharmasiri S, Estelle M: The F-box protein TIR1 is an auxin receptor. Nature 2005, 435:441-445

47. Dharmasiri N, Dharmasiri S, Weijers D, Lechner E, Yamada M, Hobbie L, Ehrismann JS, Jurgens G, Estelle M: Plant development is regulated by a family of auxin receptor F box proteins. Dev Cell 2005, 9:109-119.

48. Kepinski S, Leyser O: The Arabidopsis F-box protein TIR1 is an auxin receptor. Nature 2005, 435:446-451.

49. Ramos JA, Zenser N, Leyser O, Callis J: Rapid degradation of auxin/ indoleacetic acid proteins requires conserved amino acids of domain II and is proteasome dependent. Plant Cell 2001, 13:2349-2360.

50. Fu HY, Doelling $J \mathrm{H}$, Arendt CS: Molecular organization of the $20 \mathrm{~S}$ proteasome gene family from Arabidopsis thaliana. Genetics 1998, 149:677-692.

51. Smalle J, Kurepa J, Yang PZ: The pleiotropic role of the $26 \mathrm{~S}$ proteasome subunit RPN10 in Arabidopsis growth and development supports a substratespecific function in abscisic acid signaling. Plant Cell 2003, 15:965-980.

52. Eshraghi L, Anderson JP, Aryamanesh N, McComb JA, Shearer B, Hardy GESJ: Defence signalling pathways involved in plant resistance and phosphitemediated control of Phytophthora cinnamomi. Plant Mol Biol Rep 2014, 32:342-356

53. Eshraghi L, Anderson J, Aryamanesh N, Shearer B, McComb JA, Hardy GESJ, O'Brien PA: Phosphite primed defence responses and enhanced expression of defence genes in Arabidopsis thaliana infected with Phytophthora cinnamomi. Plant Pathol 2011, 60:1086-1095

54. Ticconi CA, Delatorre CA, Abel S: Attenuation of phosphate starvation responses by phosphite in Arabidopsis. Plant Physiol 2001, 127(3):963-972.

55. Thao HTB, Yamakawa T: Phosphite (phosphorous acid): Fungicide, fertilizer or bio-stimulator? Soil Sci Plant Nutr 2009, 55:228-234.

56. Nilsson L, Lundmark M, Jensen PE, Nielsen TH: The Arabidopsis transcription factor $P H R 1$ is essential for adaptation to high light and retaining functional photosynthesis during phosphate starvation. Physiol Plant 2012, 144:35-47. 
57. Delhaize E, Randall PJ: Characterization of a phosphate accumulator mutant of Arabidopsis thaliana. Plant Physiol 1995, 107:207-213.

58. Poirier $Y$, Thoma S, Somerville C, Schiefelbein J: A mutant of Arabidopsis deficient in xylem loading of phosphate1. Plant Physiol 1991, 97:1087-1093.

59. Vanneste S, Friml J: Auxin: a trigger for change in plant development. Cell 2009, 136:1005-1016

60. Benjamins R, Scheres B: Auxin: the looping star in plant development. Annu Rev Plant Biol 2008, 59:443-465.

61. Hay A, Barkoulas M, Tsiantis M: ASYMMETRIC LEAVES1 and auxin activities converge to repress BREVIPEDICELLUS expression and promote leaf development in Arabidopsis. Development 2006, 133:3955-3961.

62. Petricka JJ, Benfey PN: Root layers: complex regulation of developmental patterning. Curr Opin Genet Dev 2008, 18:354-361.

63. Yamada T: The role of auxin in plant-disease development. Annu Rev Phytopathol 1993, 31:253-273.

64. Hagen G, Guilfoyle T: Auxin-responsive gene expression: genes, promoters and regulatory factors. Plant Mol Biol 2002, 49:373-385.

65. Ueda M, Matsui K, Ishiguro S: Arabidopsis RPT2a Encoding the $26 \mathrm{~S}$ proteasome subunit is required for various aspects of root meristem maintenance, andregulates gametogenesis redundantly with its homolog, RPT2b. Plant Cell Physiol 2011, 52:1628-1640.

66. Ueda M, Matsui K, Ishiguro S, Sano R, Wada T, Paponov I, Palme K, Okada K: The HALTED ROOT gene encoding the $26 \mathrm{~S}$ proteasome subunit RPT2a is essential for the maintenance of Arabidopsis meristems. Development 2004, 131:2101-2111.

67. Gallois JL, Guyon-Debast A, Lecureuil A, Vezon D, Carpentier V, Bonhomme S, Guerche P: The Arabidopsis proteasome RPT5 subunits are essential for gametophyte development and show accession-dependent redundancy. Plant Cell 2009, 21:442-459.

68. Sakamoto T, Kamiya T, Sako K: Arabidopsis thaliana $26 \mathrm{~S}$ proteasome subunits RPT2a and RPT5a are crucial for zinc deficiency-tolerance. Biosci Biotechnol Biochem 2011, 75:561-567.

69. Coffey MD, Joseph MC: Effects of phosphorous acid and fosetyl-Al on the life cycle of Phytophthora cinnamomi and Phytophthora citricola. Phytopathology 1985, 75(9):1042-1046.

70. Jackson TJ, Burgess T, Colquhoun I, Hardy GESJ: Action of the fungicide phosphite on Eucalyptus marginata inoculated with Phytophthora cinnamomi. Plant Pathol 2000, 49:147-154.

71. Daniel R, Guest D: Defence responses induced by potassium phosphonate in Phytophthora palmivora-challenged Arabidopsis thaliana. Physiol Mol Plant Pathol 2006, 67(3-5):194-201.

72. Gunning TK, Conlan XA, Parker RM, Dyson GA, Adams MJ, Barnett NW, Cahill DM: Profiling of secondary metabolites in blue lupin inoculated with Phytophthora cinnamomi following phosphite treatment. Funct Plant Biol 2013, 40(11):1089-1097.

73. Florencia Machinandiarena M, Candela Lobato M, Laura Feldman M, Rau Daleo G, Balbina Andreu A: Potassium phosphite primes defense responses in potato against Phytophthora infestans. J Plant Physio/ 2012 169(14):1417-1424

74. Bari R, Pant BD, Stitt M, Scheible WR: PHO2, microRNA399, and PHR1 define a phosphate-signalling pathway in plants. Plant Physiol 2006, 141(3):988-999.

75. Carswell MC, Grant BR, Theodorou M, Harris J, Niere J, Plaxton W: The fungicide phosphonate disrupts the phosphate-starvation response in Brassica nigra seedlings. Plant Physiol 1996, 110:105-110.

76. Carswell M, Grant B, Plaxton W: Disruption of the phosphate-starvation response of oilseed rape suspension cells by the fungicide phosphonate. Planta 1997, 203:67-74.

77. Linkohr BI, Williamson LC, Fitter AH, Ottoline Leyser HM: Nitrate and phosphate availability and distribution have different effects on root system architecture of Arabidopsis. Plant J 2002, 29(6):751-760.

78. Williamson L, Ribrioux SP, Fitter AH, Leyser HM: Phosphate availability regulates root system architecture in Arabidopsis. Plant Physiol 2001, 126:875-882.

79. Bates TR, Lynch JP: Stimulation of root hair elongation in Arabidopsis thaliana by low phosphorus availability. Plant Cell Environ 1996, 19:529-538.

80. Gilbert GA, Knight JD, Vance CP, Allan DL: Proteoid root development of phosphorus Deficient lupin is mimicked by auxin and phosphonate. Ann Bot 2000, 85:921-928.
81. Byrt $P$, Grant $B$ : Some conditions governing zoospore production in axenic cultures of Phytophthora cinnamomi Rands. Aust J Bot 1979, 27:103-115.

82. Gamborg OL, Miller RA, Ojima K: Nutrient requirements of suspension cultures of soybean root cells. Exp Cell Res 1968, 50:151-158.

83. Hoagland DR, Arnon DI: The water culture method for growing plants without soil. California Agr Exp Stat Circ 1938, 347:461.

84. Wiszniewski A, Zhou W, Smith S, Bussell J: Identification of two Arabidopsis genes encoding a peroxisomal oxidoreductase-like protein and an acyl-CoA synthetase-like protein that are required for responses to pro-auxins. Plant Mol Biol 2009, 69(5):503-515.

85. Tai TH, Dahlbeck D, Clark ET, Gajiwala P, Pasion R, Whalen MC, Stall RE, Staskawicz BJ: Expression of the Bs2 pepper gene confers resistance to bacterial spot disease in tomato. Proc Natl Acad Sci USA 1999, 96(24):14153-14158.

86. Laby RJ, Kincaid MS, Kim D, Gibson SI: The Arabidopsis sugar-insensitive mutants sis 4 and sis 5 are defective in abscisic acid synthesis and response. Plant J 2000, 23(5):587-596

87. Gaude N, Nakamura Y, Scheible WR: Phospholipase C5 (NPC5) is involved in galactolipid accumulation during phosphate limitation in leaves of Arabidopsis. Plant J 2008, 56:28-39.

88. Hamburger D, Rezzonico E, Petetot JMC, Somerville C, Poirier Y: Identification and characterization of the Arabidopsis $\mathrm{PHO} 1$ gene involved in phosphate loading to the xylem. Plant Cell 2002, 14(4):889-902

89. Aung K, Lin SI, Wu CC, Huang YT, Su CL, Chiou TJ: pho2, a phosphate overaccumulator, is caused by a nonsense mutation in a MicroRNA399 target gene. Plant Physiol 2006, 141(3):1000-1011.

90. Tan X, Calderon-Villalobos LIA, Sharon M: Mechanism of auxin perception by the TIR1 ubiquitin ligase. Nature 2007, 446:640-645.

91. Sonoda Y, Sako K, Maki Y: Regulation of leaf organ size by the Arabidopsis RPT2a 19 S proteasome subunit. Plant J 2009, 60:68-78.

92. Lin YL, Sung SC, Tsai HL: The defective proteasome but not substrate recognition function Is responsible for the null phenotypes of the Arabidopsis proteasome subunit RPN10. Plant Cell 2011, 23:2754-2773.

doi:10.1186/1471-2229-14-68

Cite this article as: Eshraghi et al:: Suppression of the auxin response pathway enhances susceptibility to Phytophthora cinnamomi while phosphite-mediated resistance stimulates the auxin signalling pathway. BMC Plant Biology 2014 14:68.

\section{Submit your next manuscript to BioMed Central and take full advantage of:}

- Convenient online submission

- Thorough peer review

- No space constraints or color figure charges

- Immediate publication on acceptance

- Inclusion in PubMed, CAS, Scopus and Google Scholar

- Research which is freely available for redistribution 